Eur J Clin Chem Clin Biochem

$1995 ; 33: 323-328$

() 1995 Walter de Gruyter \& Co.

Berlin - New York

\title{
Skin Burn Injury and Oxidative Stress in Liver and Lung Tissues of Rabbit Models ${ }^{1}$ )
}

\author{
By Farideh Sabeh ${ }^{1}$, Charles R. Baxter ${ }^{2}$ and Scott J. Norton ${ }^{1}$ \\ 1 The Division of Biochemistry, Department of Biology, The University of North Texas, Denton, Texas, USA \\ 2 The Department of Surgery, The University of Texas Health Science Center at Dallas, Dallas, Texas, USA
}

(Received November 30, 1994/March 21, 1995)

Summary: The effects of burn injury (30\% of total body surface area) on the levels of oxidized and reduced glutathione, malondialdehyde, and on the activities of certain glutathione-dependent enzymes, have been determined in tissues of rabbit models. Thus, the malondialdehyde, glutathione (GSH), glutathione disulfide (GSSG) concentrations and the specific activities of glutathione peroxidase, glutathione S-transferase, and glutathione reductase were measured in liver and lung of 24-h burn rabbit models and compared to the corresponding values in 24-h sham burn (medicated, anesthetic/analgesic) rabbit models. It was found that the concentrations of malondialdehyde in liver and lung of burn models were increased by $17 \%$ and $29 \%$ respectively. Glutathione concentrations were decreased by $29 \%$ in liver and $13 \%$ in lung, and glutathione disulfide concentrations were increased by $35 \%$ in liver and $33 \%$ in lung, in burn versus sham burn models. It was also found that the specific activities of glutathione peroxidase decreased significantly, resultant to burn injury, by an average of $35 \%$ and $27 \%$ in liver and lung, respectively. Burn injury also decreased glutathione S-transferase specific activities by $14 \%$ in liver and $23 \%$ in lung tissues. In contrast, glutathione reductase specific activity was increased in liver tissues (22\%), but was decreased (19\%), as with the other enzymes studied, in lung tissues of burn models. Control model studies (no medication, no sham burn) show that these effects of burn injury are additional to effects elicited by medication associated with sham burn models. The data of this study are indicative of a major oxidative stress in liver and lung tissues due to burn injury at a remote site.

\section{Introduction}

Autooxidation processes arise from reactive oxygen species such as hydrogen peroxide, hydroxyl radicals, and superoxide radicals, generated as by-products of aerobic metabolism or other processes such as thermal injury or drug metabolism $(1-4)$. These reactive oxygen species cause autooxidation of polyunsaturated fatty acids, leading to the formation of lipid peroxides. Such peroxides have numerous deleterious effects on biological systems (5) and have been implicated in the process of aging as well as the pathogenesis of several diseases (6). There is strong evidence that the toxic products of burn oxidative

1) This research was supported by grants from Active Organics of Dallas, Texas and from The National Institutes of Health, GM 21681 . stress are systemically circulating lipid peroxides. Lipid peroxides ultimately give rise to malondialdehyde; this dialdehyde has been shown to react with proteins $(7,8)$ and amino acids (9). Nishigaki et al. (10) and Kawai et al. (11) reported significant increases in lipid peroxide levels, as measured by malondialdehyde concentration, in the serum of rats and mice, $4 \mathrm{~h}$ after burn injury to the skin. An increased level of malondialdehyde was found in the plasma of burn patients shortly following burn injury, and lasting up to 12 days postinjury (12). Further, lipid peroxides have also been reported to lead to increased vascular permeability, activation of a series of cascades with production of inflammatory mediators, lung and other systemic organ dysfunction, increased erythrocyte fragility, and immune depression $(13-16)$. 
Among the major defense processes which combat the deleterious oxidation effects resulting from reactive oxygen species are glutathione, certain glutathione-dependent enzymes; such as glutathione peroxidase ${ }^{2}$ ), glutathione S-transferase ${ }^{2}$ ), and the glutathione regenerative enzyme, glutathione reductase ${ }^{2}$ ) (17). Glutathione peroxidase, a selenium-enzyme, catalyzes the reduction of hydrogen peroxide, organic peroxides, and in the case of a liver form (18), phospholipid peroxides. Glutathione peroxidase, along with glutathione reductase, serves to detoxify a major portion of the cellular hydroperoxides and peroxides generated by reactive oxygen species (19). Certain forms of glutathione S-transferase, in addition to catalyzing conjugations of glutathione with toxic compounds (xenobiotics), including the degradation product of arachidonic acid, 4-hydroxynon-2-enal (20, $21)$, have also been shown to catalyze the reduction of organic peroxides $(22,23)$.

Depletion of cellular glutathione may reduce the cellular ability to destroy free radicals and reactive oxygen species, thereby raising the general oxidative potential in the cells. Oxidized glutathione is a physiological indicator of the activity of the intracellular defense system against reactive oxygen, and it can be used to monitor oxidant stress in vivo (24). In this investigation, we extend the study of the role of glutathione and its dependent enzymes upon the oxidative stress resultant to acute burn injury of skin. The consequences of full thickness skin burn injury, involving approximately $30 \%$ of the total body surface area, have been studied after $24 \mathrm{~h}$, on the malondialdehyde, glutathione, oxidized glutathione levels, and on the activities of certain glutathione-dependent enzymes, glutathione peroxidase, glutathione Stransferase, and glutathione reductase in liver and lung tissues of rabbit models.

\section{Materials and Methods}

\section{Materials}

Liver and lung tissues from sham burn and burn models, New Zealand white rabbits, were kindly donated by Dr. $J$. W. Horton, Professor of Surgery, University of Texas Southwestern Medical Center, Dallas, Texas. The following chemicals were purchased from Sigma Chemical Company: reduced glutathione, oxidized glutathione, 1-chloro-2,4-dinitrobenzene, $\beta$-nicotinamide adenine dinucleotide phosphate (reduced form), glutathione reductase (type III, Bakers yeast), cumene hydroperoxide, $o$-phthalaldehyde, phenylmethylsulfonyl fluoride, $\mathrm{N}$-ethylmaleimide, thiobarbituric acid, 1,1,3,3-tetramethoxypropane (malonaldehyde- bis-dimethylacetal),

\footnotetext{
2) Enzymes:

Glutathione Peroxidase (Glutathione : Hydrogen Peroxide Oxidoreductase, EC 1.11.1.9);

Glutathione Reductase (Reduced-NAD(P) : Oxidized Glutathione Oxidoreductase, EC 1.6.4.2);

Glutathione S-Transferase (RX : Glutathione R-transferase, EC 2.5.1.18)
}

and all inorganic salts and organic reagents. All enzyme assays and spectrophotometric readings were made on a Shimadzu UV-1201 or a Beckman DU-70 spectrophotometer. A Hitachi F-2000 fluorescence spectrophotometer was used for the determinations of glutathione and oxidized glutathione concentrations in tissue extracts.

\section{Rabbit burn model}

New Zealand white rabbits were housed and used in compliance with the regulations of the Animal Care Facility of the University of Texas Southwestern Medical Center. The animals were divided into 3 experimental groups: control $(n=4)$, sham $(n=7)$, and burn $(n=7)$. The control animals were given a lethal dose of sodium pentabarbital $(4 \mathrm{ml}$ of $50 \mathrm{~g} / \mathrm{l})$, and the organs were harvested immediately after death and freeze-clamped. The other two groups were anesthetized with isoflurane; central venous and thermistortipped aortic catheters were placed in the jugular vein and carotid artery. The deeply anesthetized animals were then placed in a template device, and the surface area of the shaved skin exposed through the device (on the animal's back and on each side) was immersed in $100^{\circ} \mathrm{C}$ water for 12 seconds. With this technique (25), full thickness burns comprising $30 \%$ of the total body surface area were obtained. Sham-burned rabbits were subjected to the same treatment, except they were immersed in water at room temperature. The animals were then dried, allowed to recover from anesthesia, and given Ringer's lactate solution to maintain urine output. The animals were also given an analgesic (buprenorphine, 0.05 $\mathrm{mg} / \mathrm{kg}$ ) immediately postburn, and at each succeeding 8-h interval throughout a 24-h period. These animals were then sacrificed (seven burn and seven sham-burn), and organs (lung, liver) were harvested, freeze-clamped, and stored at $-80^{\circ} \mathrm{C}$ until used for analysis. The statistical analyses of the data (mean, standard error of the mean, and $p$ value [Student $t$-test]) were calculated using the Macintosh software program, Microsoft Excell, Version 4.0.

\section{Tissue preparation for enzyme assays}

Tissues were homogenized $(100 \mathrm{~g} / \mathrm{l})$ in cold, $10 \mathrm{mmol} / \mathrm{h}$ sodium phosphate buffer, $\mathrm{pH} 7.4$, containing $100 \mu \mathrm{mol} / /$ phenylmethylsulfonyl fluoride. Homogenization was carried out using a Polytron homogenizer at a setting of 12.5 to 13.0 for 30 seconds. Homogenates were centrifuged at $25000 \mathrm{~g}$ for $30 \mathrm{~min}$, the supernatant solutions were used for the enzyme assays.

\section{Determination of tissue lipid peroxides}

Lipid peroxides, in terms of malondialdehyde produced, were determined by a method similar to that of Ohkawa et al. (26). In the standard assay, $1.0 \mathrm{ml}$ of $(100 \mathrm{~g} / \mathrm{l})$ tissue homogenate (Polytron homogenization in, $11.5 \mathrm{~g} / \mathrm{l}, \mathrm{KCl})$ was mixed with $0.4 \mathrm{ml}$ of $(80$ $\mathrm{g} / \mathrm{l})$ aqueous sodium dodecylsulfate. Then $1.0 \mathrm{ml}$ of $4.0 \mathrm{~g} / \mathrm{l}$ thiobarbituric acid solution, prepared as previously described (27), was added, and the reaction mixture was diluted to a total volume of $5.0 \mathrm{ml}$ with physiological saline. This mixture was incubated at $95^{\circ} \mathrm{C}$ in a water bath, with gentle shaking, for $60 \mathrm{~min}$. After cooling in water, $5.0 \mathrm{ml}$ of $n$-butanol-pyridine solution $(15: 1)$ was added, mixed, and centrifuged for $15 \mathrm{~min}(4000 \mathrm{~g})$ to extract the pink reaction product. The absorbance was measured. at $532 \mathrm{~nm}$, and readings were compared to a standard curve prepared from solutions of known concentrations of malondialdehyde treated as described above.

\section{Glutathione and glutathione disulfide determinations}

Tissue levels of these metabolites were determined by measurement of fluorescence emission of the 0 -phthalaldehyde reaction product with either glutathione or glutathione disulfide. Extracts were made by homogenizing $1.0 \mathrm{~g}$ of liver or lung tissue in $19 \mathrm{ml}$ of a cold solution prepared from $15 \mathrm{ml}$ of $100 \mathrm{mmol} / \mathrm{l}$ phosphate$5 \mathrm{mmol} / 1$ EDTA buffer, $\mathrm{pH} 8.0$, and $4.0 \mathrm{ml}$ of $2.73 \mathrm{~mol} / 1 \mathrm{phospho-}$ 
ric acid. The precipitated proteins were then removed by centrifugation at $4{ }^{\circ} \mathrm{C}$ at $30000 \mathrm{~g}$ for $30 \mathrm{~min}$, and the supernatant solutions were used for the glutathione and glutathione disulfide assays.

Glutathione and glutathione disulfide were determined by the method of Cohn \& Lyle (28) as modified by Hissin \& Hilf (29). Fluorescence measurements were compared to a standard curve constructed from fluorescence values obtained for known concentrations of glutathione or glutathione disulfide. Recovery studies were conducted on several tissue samples by spiking the tissue extracts with known quantities of glutathione or glutathione disulfide. In all cases recoveries of both glutathione and glutathione disulfide ranged from 90 to $95 \%$.

\section{Enzyme assays}

Glutathione peroxidase activity, using cumene hydroperoxide as substrate, was determined by the coupled enzyme method of Paglia \& Valentine (30) with minor modifications. The standard assay mixture contained in $1.0 \mathrm{ml}$ final volume: $50 \mathrm{mmol} / \mathrm{l}$ Tris buffer, $\mathrm{pH} 7.4 ; 0.14 \mathrm{mmol} / \mathrm{h} \beta$-nicotinamide adenine dinucleotide phosphate (reduced form, NADPH); $1.0 \mathrm{mmol} / \mathrm{l}$ glutathione; $1.0 \mathrm{kU} / \mathrm{l}$ glutathione reductase; $0.5 \mathrm{mmol} / 1$ cumene hydroperoxide; and a rate-limiting amount of glutathione peroxidase (tissue homogenate supernatant fraction). For each determination a non-enzymatic glutathione oxidation rate was determined in the absence of glutathione peroxidase activity; the value obtained was subtracted from the rate observed in the presence of glutathione peroxidase activity. One unit of glutathione peroxidase activity is expressed as the amount of enzyme required to oxidize $1.0 \mu \mathrm{mol} / \mathrm{min}$ of $\mathrm{NADPH}$ under the assay conditions.

Glutathione S-transferase activity was measured by the procedure of Habig et al. (31). One unit of activity is defined as the amount of enzyme producing $1.0 \mu \mathrm{mol} / \mathrm{min}$ of thioether (from 1-chloro2,4-dinitrobenzene), as measured spectrophotometrically at 340 nm. Glutathione reductase activity was determined according to the method of Carlberg et al. (32). One unit of enzyme activity is defined as that amount of enzyme which catalyzes the oxidation of $1.0 \mu \mathrm{mol} / \mathrm{min}$ of NADPH.

\section{Protein determinations}

Protein concentrations in tissue homogenate supernatant fractions were determined by the method of Bradford (33), employing bovine serum albumin as a protein standard. Metabolite concentrations (malondialdehyde, glutathione, and glutathione disulfide) are reported in terms of $\mathrm{nmol}$ or $\mu \mathrm{mol}$ per $\mathrm{g}$ of tissue (wet weight); when calculated in terms of amounts per $\mathrm{mg}$ of protein, the comparative levels of these metabolites remain essentially the same.

\section{Results}

Lipid peroxide levels were measured, in terms of malondialdehyde produced therefrom $(34,35)$, in liver and lung tissues of burn, sham burn, and control rabbit models, $24 \mathrm{~h}$ post-burn or post-sham burn. Liver and lung tissues from burn models have an average increase of $17 \%(\mathrm{p}<0.001)$ and $29 \%(\mathrm{p}<0.001)$ in malondialdehyde levels, respectively, when compared to sham burn models. The malondialdehyde level of the burn models increased by $26 \%$ and $55 \%$ in the liver and lung respectively, when compared to control models $(p<0.001)$. The effects of anesthetic/analgesic on the liver and lung malondialdehyde levels were increases of $8 \%(p<0.03)$ and $20 \%(p<0.001)$, respectively (compared with con- trol model values). These data are summarized in table 1 .

Glutathione and glutathione disulfide determinations of liver and lung tissues from 24-h burn, sham burn, and control models are also summarized in table 1 . In liver tissues from burn models there is an average $29 \%$ $(p<0.001)$ decrease in glutathione concentration accompanied by an average $35 \%(p<0.01)$ increase in glutathione disulfide concentration when compared to sham burn models. In the liver tissues of control models, compared to burn models, there is an average 2-fold decrease $(p<0.001)$ in glutathione concentration and a 2 -fold increase $(p<0.001)$ in glutathione disulfide concentration. Sham burn also caused some alteration in the levels of these metabolites in the liver; a $30 \%$ $(\mathrm{p}<0.001)$ decrease in glutathione and a $48 \%$ $(p<0.01)$ increase in glutathione disulfide levels, compared to control values. The corresponding values for glutathione in burn lung compared to sham burn and control lung give a $13 \%(\mathrm{p}<0.07)$ and $32 \%(\mathrm{p}<0.01)$ decrease, respectively. The concentration of glutathione disulfide in burn lung tissue increased by $33 \%$ $(p<0.001)$ and $50 \%(p<0.001)$ over sham burn and control values, respectively. The glutathione and glutathione disulfide levels of sham burn lung versus control lung show a $22 \%(p<0.001)$ decrease and a $13 \%$ $(p=0.1)$ increase, respectively.

The glutathione-dependent enzymes, glutathione peroxidase, glutathione S-transferase, and glutathione reductase, were also studied in 24-h tissues from liver and lung in burn, sham burn, and control rabbit models. The results are summarized in table 2 . The values given are statistically significant. The glutathione peroxidase specific activity is decreased by an average of $35 \%$ $(p<0.001)$ in burn liver, and by $27 \%(p<0.001)$ in burn lung in comparison to sham burn. The specific ac-

Tab. 1 Malondialdehyde, GSH and GSSG levels in control, sham burn and burn, liver and lung tissues.

\begin{tabular}{lllll}
\hline Tissue & $\begin{array}{l}\text { Treat- } \\
\text { ment }\end{array}$ & $\begin{array}{l}\text { Malondi- } \\
\text { aldehyde } \\
\text { (nmol/g } \\
\text { tissue) }\end{array}$ & $\begin{array}{l}\text { GSH } \\
(\mu \mathrm{mol} / \mathrm{g} \\
\text { tissue) }\end{array}$ & $\begin{array}{l}\text { GSSG } \\
(\mu \mathrm{mol} / \mathrm{g} \\
\text { tissue) }\end{array}$ \\
\hline Liver & Control & $71.5 \pm 1.32$ & $8.00 \pm 0.09$ & $1.15 \pm 0.06$ \\
& Sham & $77.3 \pm 1.70$ & $5.60 \pm 0.20$ & $1.70 \pm 0.10$ \\
& Burn & $90.2 \pm 1.80$ & $4.00 \pm 0.30$ & $2.30 \pm 0.20$ \\
Lung & $\begin{array}{l}\text { Control } \\
\text { Sham }\end{array}$ & $81.5 \pm 1.03$ & $3.54 \pm 0.07$ & $0.88 \pm 0.03$ \\
& Burn & $126.0 \pm 2.03$ & $2.40 \pm 0.09$ & $1.32 \pm 0.03$ \\
\hline
\end{tabular}

See Materials and Methods for experimental details. Data are expressed as mean \pm SEM, $(n=4$ for control, 7 for sham, and 7 for burn). Statistical significances, $p$ values, are given in the Results section. 
Tab. 2 GSH-dependent enzyme specific activities in control, sham burn and burn, liver and lung tissues.

\begin{tabular}{lllll}
\hline Tissue & $\begin{array}{l}\text { Treat- } \\
\text { ment }\end{array}$ & $\begin{array}{l}\text { Glutathione } \\
\text { peroxidase } \\
\text { (mU/mg } \\
\text { protein) }\end{array}$ & $\begin{array}{l}\text { Glutathione } \\
\text { S-transferase } \\
\text { (mU/mg } \\
\text { protein) }\end{array}$ & $\begin{array}{l}\text { Glutathione } \\
\text { reductase } \\
\text { (mU/mg } \\
\text { protein) }\end{array}$ \\
\hline Liver & Control & $911 \pm 81$ & $5228 \pm 40$ & $69.3 \pm 1.4$ \\
& Sham & $904 \pm 40$ & $5200 \pm 160$ & $72.1 \pm 2.6$ \\
& Burn & $591 \pm 47$ & $4470 \pm 120$ & $88.2 \pm 2.0$ \\
Lung & Control & $166 \pm 7.3$ & $819 \pm 13$ & $69.1 \pm 1.5$ \\
& Sham & $162 \pm 5.2$ & $830 \pm 30$ & $69.4 \pm 1.7$ \\
& Burn & $118 \pm 3.4$ & $640 \pm 20$ & $56.1 \pm 2.0$ \\
\hline
\end{tabular}

See Materials and Methods for experimental details. Data are expressed as mean \pm SEM, $(n=7$ for burn and sham burn, $n=4$ for control). Statistical significances, $p$ values, are given in the Results section.

tivity of glutathione S-transferase is decreased by an average of $14 \%(p<0.01)$ and $23 \%(p<0.001)$ in the liver and lung of burn animal models, respectively, compared to sham burn. On the other hand, the specific activities of glutathione reductase are increased by an average of $22 \%(p<0.001)$ in the livers of models subjected to thermal injury, when compared to sham burn. Although the actual difference in glutathione reductase specific activities of burn and sham burn models are rather small, statistical analyses indicate that these differences are significant. In contrast, in lung tissues of burn and sham burn models, the glutathione reductase specific activities reflect the trends of the other two glutathione-dependent enzymes studied; there is an average $19 \%(p<0.001)$ decrease in specific activity in burn models as compared to sham burn models. No differences were found in these enzyme activities which could relate to effects of anesthetic/analgesic (control versus sham). Others have reported differences in glutathione metabolism and in glutathione-dependent enzyme activity responses to various chemical challenges in lung and liver tissues (36). In a separate study we measured the activities of two glutathione-independent, anti-oxidative enzymes (superoxide dismutase and catalase) in liver and lung homogenates of control, sham burn and burn models. The activities of these enzymes within the three groups were not statistically different.

\section{Discussion}

In the present study, the malondialdehyde levels, derived from the breakdown of fatty acid peroxide moieties, are increased in both liver and lung of burn models, when compared with malondialdehyde levels in sham burn animals (tab. 1). This increase could result from deleterious oxidative effects on membrane lipids $(10,11)$ at sites remote from the site of injury. Thus, hydrogen peroxide (or other organic peroxides), hydroxyl radicals or superoxide radicals, produced at the site of injury, could oxidize fatty acid moieties of membrane lipids at distal sites. Another explanation could be that lipid peroxides, produced from damaged cell membranes at the injury site, enter the circulation and become incorporated into membrane lipids in other tissues, such as liver and lung (37). Yet another explanation could' relate to the influx into liver and lung tissues of phagocytes, such as neutrophils, in response to the burn injury, which could generate reactive oxygen species $(38,39)$. A previous study by others in this laboratory (unpublished), involving skin burns in rabbit models, showed that circulating neutrophils increase approximately $30 \%$ within $4 \mathrm{~h}$ following burn injury, and remain at that level at least $24 \mathrm{~h}$. As also seen in table 1, malondialdehyde levels in both liver and lung of control rabbits (no sham burn, no anesthetic/ analgesic) are the lowest of the test groupings. It is evident that there are increases in peroxide formation due to oxidative processes involving the anesthetics/analgesics (sham burn). However, these findings do not negate the evidence of even greater oxidative stress (highest malondialdehyde levels) found in the burn animal group.

Since glutathione-dependent enzymes (i. e., glutathione peroxidase) play a major role in decreasing the levels of various peroxides, it would not be surprising that the oxidative insult evidenced by the increases in malondialdehyde in burn liver and lung would have an effect on the relative amounts of the glutathione and glutathione disulfide. The results in this study indicate this to be the case. The glutathione disulfide/glutathione ratio in sham burn liver is 0.30 ; the ratio increases almost 2-fold, to 0.58 in burn liver. Similarly, the glutathione disulfide/ glutathione ratio in sham burn lung is 0.36 ; in burn lung the ratio is 0.55 , an increase of over 1.5 -fold (data derived from tab. 1).

It is noteworthy that the glutathione disulfide levels in both liver and lung of sham burn models are extraordinarily high and give testimony to an oxidative stress situation (40). Thus, the glutathione disulfide/glutathione ratio in the control groups for liver and lung were found to be 0.14 and 0.25 , respectively (data derived from tab. 1). The value for this ratio in normal rat liver has been reported to be 0.05 (41). The low glutathione and high glutathione disulfide levels in both burn and sham burn animals, when compared to control rabbit tissues, could well reflect a depletion of glutathione (and increase in glutathione disulfide) in liver and lung tissues via detoxification processes of xenobiotic anesthetic and analgesic supplements (isoflurane and buprenorphine, respectively) during the 24-h period (see Materials and Methods). It has been established that a variety of drugs cause oxidative stress $(2,42)$; relief of 
such stress is addressed, in part, through the action of glutathione-dependent enzymes. Glutathione peroxidase produces glutathione disulfide, which competes with glutathione conjugates (from glutathione S-transferase activity) for a common carrier to be transported from cells (43). Both of these processes could lead to the accumulation of intracellular glutathione disulfide.

In the studies of glutathione-dependent enzymes from liver and lung of burn and sham burn models, (tab. 2) the results are consistent with an assumption that the burn models have experienced oxidative damage of tissue protein and/or membranes at sites remote from the thermal injury site. There is one exception in these results, however. In the case of liver tissue, there is a small, but statistically significant increase in glutathione reductase activity in burn versus sham burn models. There is evidence that some enzyme activities are increased when the glutathione disulfide/glutathione ratio increases (oxidative stress situation). This has been suggested as an explanation for the increased blood glutathione reductase activity in the uraemic rat where the glutathione disulfide/glutathione ratio is increased (41). On the other hand, one of the causes of a decrease in an enzyme's activity under oxidative stress is the formation of protein disulfide bridges, with consequent diminution of catalytic capability (44). The difference in the responses to oxidative stress of glutathione reductase in liver and lung tissue in this study are presently unclear. We found that the in vitro incubation of liver homogenates, obtained from control models, with hydrogen per-

\section{References}

1. Klebanoff SJ. Oxygen metabolism and the toxic properties of phagocytes. Ann Intern Med 1980; 93:480-9.

2. Mimnaugh EG, Trush MA, Gram TE. Stimulation by adriamycin of rat heart and liver microsomal NADPH-dependent lipid peroxidation. Biochem Pharmacol 1981; 30:2797-804.

3. Parks D, Granger D. Xanthine oxidase; biochemistry, distribution, and physiology. Acta Physiol Scand 1986; 598:87-99.

4. Egan R, Gale P, Baptist E. Oxidation reactions by prostaglandin cyclooxygenase hydroperoxidase. J Biol Chem 1981; 250:7352-61.

5. Sevanian A, Hochstein P. Mechanisms and consequences of lipid peroxidation in biological systems. Ann Rev Nutr 1985; 5:365-90.

6. Pryor W. Xenobiotic metabolism, nutrition effects. In: Finley JW, Schwass D, editors. American Chemical Society. Washington D.C., 1985:77-96.

7. Draper $\mathrm{HH}$, Hadley $\mathrm{N}$, Lissemore L, Laing NM, Cole RP. Identification of $\mathrm{N}-\varepsilon$-(2-propenal) lysine as a major urinary metabolite of malondialdehyde. Lipids 1988; 23:626-8.

8. Lee HS, Csallany AS. Measurement of free and bound malondialdehyde in vitamin E-deficient and supplemented rat liver tissues. Lipids 1987; 22:104-7.

9. Chio KS, Tappel AL. Synthesis and characterization of the fluorescent products derived from malonaldehyde and amino acids. Biochemistry 1969; 8:2821-7. oxide at two different concentrations $(0.01$ and 0.10 $\mathrm{mmol} / \mathrm{l}$ ) did not significantly alter the activities of the three enzymes studied herein.

This study gives strong evidence that full thickness skin burns cause significant effects on the oxidation-reduction status of glutathione in liver and lung tissues of animal models. It is reasonable to propose that the increased glutathione disulfide/glutathione ratios reflect the organ's response to ameliorate the deleterious effects of reactive oxygen species (as reflected by increased malondialdehyde levels) produced at the site of the burn injury. It is also apparent that when the burn injury is massive ( $30 \%$, total body surface area, in this study), organ response to oxidative damage in a $24-\mathrm{h}$ period may be inadequate to fully compensate for the insult to the organism. The residual metabolite and antioxidant enzyme levels determined in this study generally support this conclusion. Therapeutic amelioration of burn injury consequences in peripheral tissues could well invoke methodologies that correct for the related increase in glutathione disulfide/glutathione ratios, since the oxidation-protective glutathione-dependent enzymes, glutathione peroxidase and glutathione S-transferase, demand high levels of glutathione for optimal activity.

\section{Acknowledgements}

We are indebted to Active Organics of Dallas, Texas, and the National Institutes of Health (GM 21681) for financial support for this research.
10. Nishigaki I, Hagihara M, Hiramatsu M, Izawa Y, Yagi K. Effect of thermal injury on lipid peroxide levels of rat. Biochem Medicine 1980; 24:185-9.

11. Kawai S, Komura J, Asada Y, Niwa Y. Experimental buminduced changes in lipid peroxide levels, and activity of superoxide dismutase and glutathione peroxidase in skin lesion, serum, and liver of mice. Arch Dermatol Res 1988; 280:171-5.

12. Sasaki J, Cottam GL, Baxter CR. Lipid peroxidation following thermal injury. J Burn Care Rehab 1983; 4:251-4.

13. Loebl EC, Baxter CR, Curreri PW. The mechanism of erythrocyte destruction in the early post-burn period. Ann Surg $1973 ; 178: 681-6$

14. Horton JW. The contribution of oxygen free radicals and lipid peroxidation to cardiac dysfunction after burn injury. J Vasc Surg. In press.

15. Kuo W, Horton JW, Walker $\mathrm{P}$, Geldon $\mathrm{D} . \mathrm{O}_{2}$ free radicals mediate post-burn cardiac cell membrane dysfunction. FASEB J 1993; 7(3):A421.

16. Halliwell B. Oxidants and human disease, some new concepts. FASEB J 1987; 1:358-64.

17. Meister A, Anderson ME. Glutathione. Ann Rev Biochem $1983 ; 52: 711-60$.

18. Ursini $F$, Maiorino $M$, Valente $M$, Gregolin C. Purification from pig liver of a protein which protects liposomes and biomembranes from peroxidative degradation and exhibits gluta- 
thione peroxidase activity on phosphatidylcholine hydroperoxides. Biochim Biophys Acta 1982; 710:197-211.

19. Chance B, Sies H, Boveris A. Hỹdroperoxide metabolism in mammalian organs. Physiol Rev 1979; 59:527-605.

20. Benedetti A, Comporti M, Esterbauer H. Identification of 4hydroxynonenal as a cytotoxic product originating from the peroxidation of liver microsomal lipids. Biochim Biophys Acta 1980; 620:281-96.

21. Esterbauer H, Cheeseman KH, Dianzani MU, Poli G, Slater TF. Separation and characterization of the aldehydic products of lipid peroxidation stimulated by $\mathrm{ADP}-\mathrm{Fe}^{2+}$ in rat liver microsomes. Biochem J 1982; 208:129-40.

22. Lawrence RA, Burk RF. Glutathione peroxidase activity in selenium deficient rat liver. Biochem Biophys Res Commun 1976; 71:952-8.

23. Prohaska JR, Ganther HE. Selenium and glutathione peroxidase in developing rat brain. J Neurochem 1976; 27:1379-87.

24. Hughes H, Jaeschke H, Mitchell JR. Measurement of oxidant stress in vivo. In: Packer L, Glazer A, editors. Methods in enzymology. San Diego, CA, Academic Press, 1990; 186:681-5.

25. Horton JW, White DJ, Baxter CR. Hypertonic saline dextran resuscitation of thermal injury. Ann Surg 1990; 221:301-11.

26. Ohkawa $\mathrm{H}$, Ohishi $\mathrm{N}$, Yagi $\mathrm{K}$. Assay for lipid peroxides in animal tissues by thiobarbituric acid reaction. Anal Biochem 1979; 95:351-8.

27. Yagi K. A simple fluorometric assay for lipoperoxide in blood plasma. Biochem Med 1976; 15:212-6.

28. Cohn VH, Lyle J. A fluorometric assay for glutathione. Anal Biochem 1966; 14:434-40.

29. Hissin PJ, Hilf R. A fluorometric method for determination of oxidized and reduced glutathione in tissues. Anal Biochem 1976; 74:214-26.

30. Paglia DE, Valentine WN. Studies on the quantitive and qualitative characterization of erythrocyte glutathione peroxidase. J Lab Clin Med 1967; 70:158-69.

31. Habig WH, Pabst MJ, Jakoby WB. Glutathione S-transferases. The first enzymatic step in mercapturic acid formation. J Biol Chem 1974; 249:7130-9.

32. Carlberg I, Mannervik B. Glutathione. In: Meister A, editor. Methods in enzymology. Orlando, FL, Academic Press, $1985 ; 113: 484-9$.

33. Bradford MM. A rapid and sensitive method for the quantitation of microgram quantities of protein utilizing the principle of protein-dye binding. Anal Biochem 1976; 72:248-54.
34. Esterbauer H, Schaur RJ, Zollner H. Chemistry and biochemistry of 4-hydroxynonenal, malonaldehyde and related aldehydes. Free Radic Biol Med 1991; 11:81-128.

35. Dahle LK, Hill EG, Holman RT. The thiobarbituric acid reaction and the autoxidation of polyunsaturated fatty acid methyl esters. Arch Biochem Biophys 1962; 98:253-60.

36. Smith AC, Boyd MR. Preferential effects of 1,3-bis-(2-chloroethyl)-1-nitrosourea (BCNU) on pulmonary glutathione reductase and glutathione/glutathione disulfide ratios: possible implications for lung toxicity. J Pharmacol Exp Ther 1984; 229:658-63.

37. Christophersen BO. Formation of monohydroxypolyenic fatty acids from lipid peroxides by a glutathione peroxidase. Biochim Biophys Acta 1968; 164:35-46.

38. Zapata-Sirvant $R$, Hansbrough JF. Temporal analysis of human leukocyte surface antigen expression and neutrophil respiratory burst activity after thermal injury. Burns 1993; 19:5-11.

39. Cioffi W, Burlesom D, Jordan B, Mason A, Pruitt B. Granulocyte oxidative activity after thermal injury. Surgery 1992; $112: 860-5$

40. Brigelius $R$, Lenzen $R$, Sies $H$. Increase in hepatic mixed disulfide levels elicited by paraquat. Biochem Pharmacol 1982; 31:1637-41.

41. Yeung HK. Effects of glycerol-induced acute renal failure on tissue glutathione and glutathione-dependent enzymes in the rat. Meth Find Exp Clin Pharmacol 1991; 13:23-8.

42. Rosen GM, Singletary WV, Rauckman EJ, Killenberg PG. Acetaminophen hepatotoxicity. Biochem Pharmacol 1983; $32: 2053-9$

43. Akerboom TPM, Bilzer M, Sies H. Competition between transport of glutathione disulfide (GSSG) and glutathione Sconjugates from perfused rat liver in the bile. FEBS Lett $1982 ; 140: 73-6$.

44. Nishihara T, Maeda H, Okamoto KI, Oshida T, Mizoguchi T, Terada T. Inactivation of glutathione S-transferase by SS/SH exchange reactions with biological disulfides. Biochem Biophys Res Commun 1991; 174:580-5.

Scott J. Norton, Ph. D.

The Division of Biochemistry

P. O. Box 5218

The University of North Texas

Denton, Texas 76203-0218

U.S.A. 